\title{
Serum Growth Hormone Levels and the Response of Diabetic Retinopathy to Pituitary Ablation*
}

\author{
A. D. WRIGHT, $\dagger$ M.B., M.R.C.P. ; E. M. KOHNER, $\ddagger$ M.B., M.R.C.P. ; N. W. OAKLEY, $§ \dagger \dagger$ M.B., M.R.C.P. \\ M. HARTOG, || D.M., M.R.C.P. ; G. F. JOPLIN, I PH.D., M.R.C.P. ; T. RUSSELL FRASER,** M.D., F.R.C.P.
}

\begin{abstract}
Summary : Serum growth hormone levels were measured during insulin tolerance tests in 36 patients after yttrium-90 pituitary implantakion for diabetic retinopathy. The response of the new blood vessels was more clearly related to lass of growth hormone function than was the improvement of retinal haemorrinages and microaneurysms. The overall response of the retinopathy was greatest when growth hormone function was lost.

Since the loss of growth hormone function was related to the loss of other aspects of anterior pituitary function, a unique role of growth hormone in the response of diabetic retinopathy to pituitary ablation could not be established.
\end{abstract}

\section{Introduction}

The beneficial effect of induced hypopituitarism on the progress of some aspects of diabetic retinopathy has been shown by a number of authors. The techniques used to reduce pituitary function include implantation of radioactive yttrium (Joplin et al., 1967), transfrontal hypophysectomy (Luft, 1962 ; Ray et al., 1968), transsphenoidal hypophysectomy (Fankhauser et al., 1966), pituitary stalk section (Field et al., 1962), and heavy particle irradiation (Linfoot, 1967). The explanation of this beneficial effect is not known. Field (1965) and Teuscher et al. (1966) suggested that near complete elimination of anterior pituitary function gave the best results. There have, however, been few reported studies on the effect of these procedures on individual pituitary functions and on the relation of the loss of particular functions to the response of the retinopathy. In one such study Powell et al. (1966) could find no relation between the loss of growth hormone secretion and the retinopathy response, whereas Teuscher et al. (1967) found a better response in those patients with low growth hormone levels.

In the series of patients treated at Hammersmith Hospital by pituitary implantation with yttrium-90 it was found that a definite endocrine deficit was usually followed by some improvement of retinopathy, while the best responses generally occurred in patients showing the most profound degrees of hypopituitarism (Joplin et al., 1967). Growth hormone measurements were not considered in this previous analysis; however, the pituitary function of some of these patients has now been studied in more detail, both to look for a possible relation between retinopathy response and loss of growth hormone secretion, and also to correlate loss of growth hormone secretion with that of other pituitary endocrine functions.

\footnotetext{
- Based on a paper read to the Spring Meeting of the Medical Scientific Section of the British Diabetic Association, Oxford, 1968.

t M.R.C. Junior Research Fellow.

† Honorary Registrar.

5 Registrar.

II Senior Registrar.

Lecturer in Medicine.

* Professor of Clinical Endocrinology.

t† Present address: Department of Medicine, Middleser Hospital, London W.1. Department of Medicine, Royal Postgraduate Medical School, London
W.12.
}

\section{Patients Studied \\ Methods}

Thirty-six patients with diabetic retinopathy were studied, on whom 40 pituitary implants with yttrium-90 had been performed between November 1960 and January 1968 . The implants were planned to give three dose levels specified at the gland surface; this was 50,000 rads in seven patients, 150,000 rads in 30 , and 300,000 rads in three. Four patients were reimplanted 5 to 13 months after an initial implant which had failed to induce hypopituitarism.

Diabetic control was maintained as tightly as feasible in each patient after operation. Those few patients referred for implantation in whom control was poor had an initial period during which the best possible control was imposed; implant was performed if the retinopathy remained severe enough to meet the criteria. Diabetic control was similar before and after implantation.

For the present study all available patients who fulfilled the following criteria were selected: (1) growth hormone secretory reserve had been measured three months or more after implant, using the stimulus of insulin-induced hypoglycaemia, in which adequate hypoglycaemia, defined as a venous blood sugar of less than $50 \mathrm{mg} . / 100 \mathrm{ml}$. (Fraser and Wright, 1968), had been achieved ; (2) photographic assessment of the retinopathy had been made before implant and about one year later (range 3 to 27 months); and (3) before implantation at least one eye showed treatable retinopathy with visual acuity $6 / 24$ (Snellen) or better, the macula was not threatened by fibrous retinitis proliferans, and visual symptoms were not principally due to hard exudates.

\section{Ophthalmic Assessment}

Detailed retinal assessments were made in 56 eyes. Each eye was assessed separately before and after the implant; thus after the 40 implants there was a possible total of 80 eyes for assessment. However, 24 eyes were excluded either because photographic assessment could not be made before implant or because our current assessment of photographs taken before implant showed that the retinopathy would not now be classified as treatable as defined above.

The individual features of the retinopathy were each graded into five grades of severity. This was done by comparing the colour photographs taken on a Zeiss retinal camera with a set of standard photographs of increasing severity (Oakley et al., 1967). For each eye three different representative fields were assessed (occasionally only two fields could be used), and particular care was taken to assess exactly the same fields in all subsequent evaluations. The average grade of the retinopathy feature in the three fields was recorded as the grade of that eye. Only two of the features which can be graded in this way have been found to be both potentially reversible and also amenable to reliable grading-new vessels (including dilated capillaries) and retinal haemorrhages (and microaneurysms ${ }^{1}$ ).

Based on the assessment of visual acuity, and this grading of new vessels and retinal haemorrhages, an "overall response"

\footnotetext{
I As microaneurysms are at times indistinguishable they have been included in this feature, which for simplification is referred to later as "retinal haemorrhages."
} 
of an eye has been derived in terms of all three features. This is defined as follows: (a) Improved: mean grade for new vessels and retinal haemorrhages better by 1 or more and neither worse by 0.5 or more, and visual acuity within one line of the initial value, or better. Where preimplant severity is less than grade 1, a complete loss of the feature is accepted. (b) Unchanged: mean grades for new vessels and retinal haemorrhages both within +0.4 to -0.9 of the initial value, and visual acuity within one line. (c) Worse: eyes failing to meet either of the above requirements.

\section{Assessment of Pituitary Function}

The methods of endocrine testing were based on those described by Joplin et al. (1965). It has now become possible to grade growth hormone secretory reserve and adrenal function as normal, reduced reserve, decreased, and maximally decreased.

The peak serum growth hormone during the insulin tolerance test was regarded as normal if over $20 \mathrm{~m} \mu \mathrm{g} . / \mathrm{ml}$., reduced reserve $5-20 \mathrm{~m} \mu \mathrm{g} . / \mathrm{ml}$., decreased $1-5 \mathrm{~m} \mu \mathrm{g} . / \mathrm{ml}$., and maximally decreased if $1 \mathrm{~m} \mu \mathrm{g} . / \mathrm{ml}$. or less. Growth hormone was measured by radioimmunoassay with modifications of the method described by Hartog et al. (1964). Results were expressed in terms of the M.R.C. Standard "A " preparation.

Adrenal function was regarded as normal if there was a normal rise-that is, an increment of $10 \mathrm{mg} . / 24$ hours or doubling-of urinary 17-oxogenic steroids after metyrapone; reduced reserve if the basal levels of 17-oxogenic steroids were normal-that is, greater than $4 \mathrm{mg}$. $/ 24$ hours-but there was not a normal response to metyrapone; decreased if the basal output was reduced and a cortisol withdrawal syndrome occurred more than five days after stopping steroids; and maximally decreased if symptoms on cortisol withdrawal occurred within five days.

Thyroid function was divided into three grades-normal, hypothyroid both clinically and on testing, and an intermediate group in which all criteria of hypothyroidism were not reached.

\section{Results}

Relation of Growth Hormone Reserve to the Response of Individual Features of Retinopathy.-The relation of the loss of growth hormone reserve to the change in ophthalmic grading
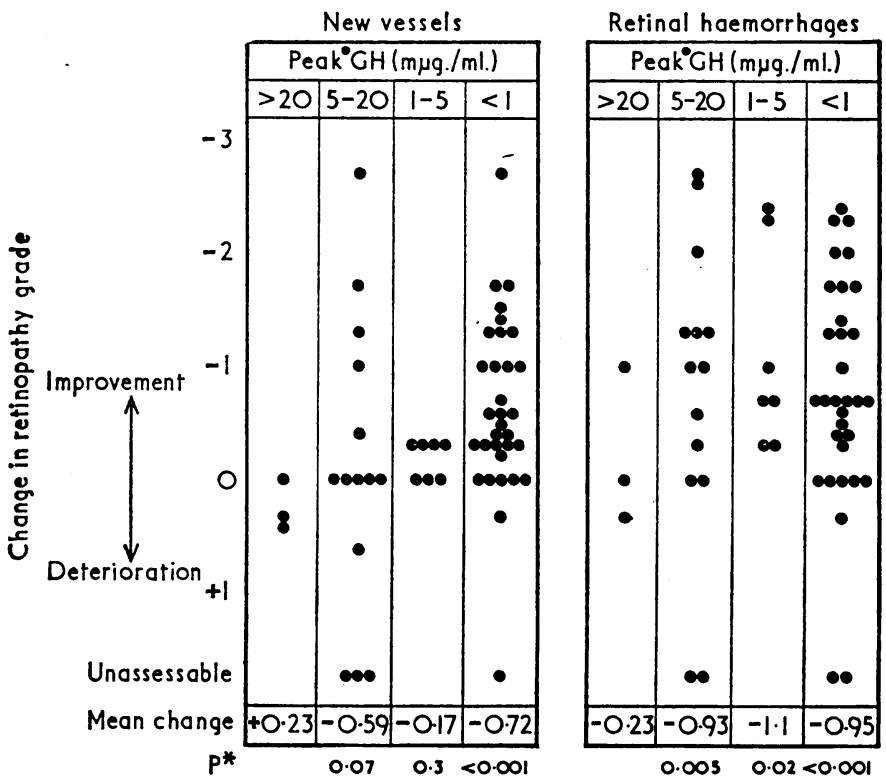

Fig. 1.-Serum growth hormone and change In reversible features of diabetic retinopathy in individual eyes after pituitary implantation. Peak serum growth hormone level during an insulin tolerance test. Significance of differences between the mean grading score before implant compared with the score after implant. of new vessels and retinal haemorrhages in each eye is shown in Fig. 1. New vessels improved when growth hormone reserve was maximally decreased. Some improvement was noted when growth hormone reserve was only decreased or reduced, but this improvement was not significant. The mean response in the maximally decreased growth hormone grade was probably better when compared with the mean response of all other growth hormone grades combined $(P=0.06)$.

Pituitary implantation lowering growth hormone reserve below the normal range also had a beneficial effect on retinal haemorrhages. Complete loss of growth hormone reserve, however, was not essential because the response when growth hormone reserve was maximally reduced was no better than the response in the other growth hormone grades $(P=0.3)$.

Relation of Growth Hormone Reserve to Overall Response of Retinopathy.-The relation of the loss of growth hormone function to the overall response of the retinopathy in individual eyes is shown in Fig. 2. The percentage of eyes that improved,

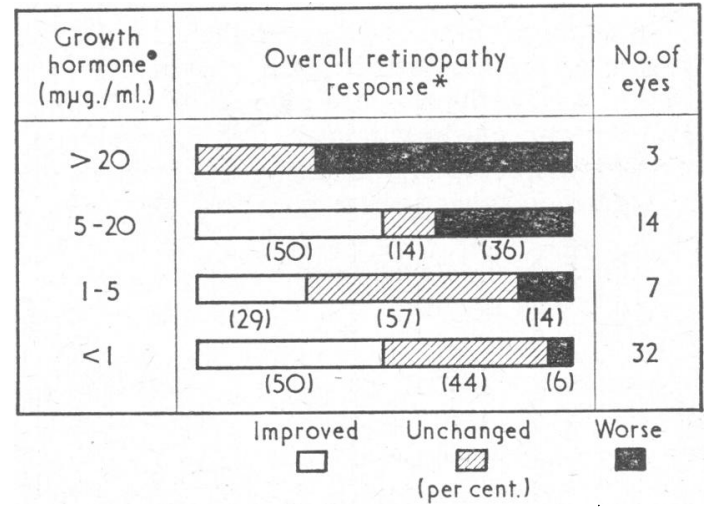

FIG. 2.-Serum growth hormone and overall response of diabetic retinopathy to pituitary ablation. Peak serum growth hormone level during an insulin tolerance test. * All " treatable" eyes at one year ( 3 to 27 months) after implant.

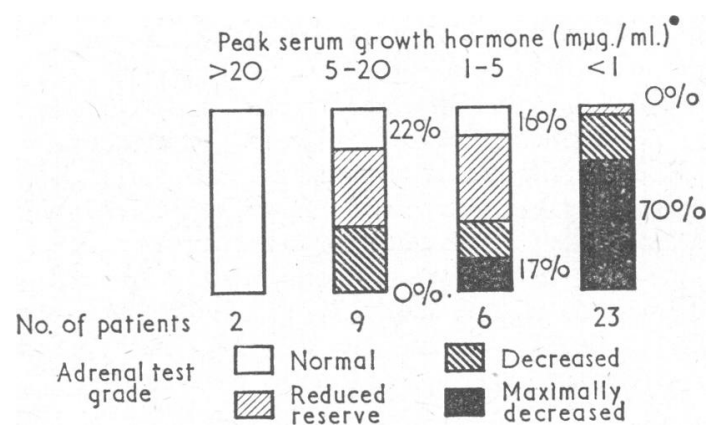

Fig. 3.-Serum growth hormone and adrenal function after pituitary implantation for diabetic retinopathy. OPeak serum growth hormone level during an insulin tolerance test.

remained unchanged, or became worse is shown for each grade of growth hormone reserve. The percentage of eyes improving and remaining unchanged increased as growth hormone reserve was lost, with a corresponding reduction in the number of eyes becoming worse. The numbers were insufficient for the normal growth hormone grade to be compared with other grades. When growth hormone reserve was reduced, $64 \%$ of eyes improved or remained unchanged and $36 \%$ became worse ; when growth hormone reserve was maximally decreased, $94 \%$ improved or remained unchanged and $6 \%$ became worse. The number of eyes becoming worse in the maximally decreased growth hormone grade was significantly less than in the other grades $(\mathrm{P}<0.05)$.

Relation of Growth Hormone Reserve to Other Tests of Pituitary Function.-The relation of growth hormone reserve to adrenal function is shown in Fig. 3. The percentage of 
patients having the four test grades of adrenal function has been plotted within each growth hormone grade. As growth hormone reserve diminished there was a progressive loss of adrenal function, but only $70 \%$ of those with maximally decreased growth hormone had maximally reduced adrenal function.

The less precise test grades of thyroid function did not relate as clearly to the loss of growth hormone reserve, but in the maximally decreased growth hormone grade 20 of the 22 patients $(91 \%)$ showed subnormal thyroid function. Growth hormone reserve was inversely correlated with the percentage fall of insulin dose after implantation $(r=0.5, P<0.005)$.

\section{Discussion}

The present study was undertaken to see whether there was any evidence that loss of growth hormone reserve was related to improvement in diabetic retinopathy after pituitary implantation. A better response, particularly of new vessels, was found when growth hormone reserve was maximally decreased. A similar response of new vessels has been shown in some of these patients by means of fluorescence photography (Kohner et al., 1967) ; only in patients in whom the pituitary had been completely ablated did some of the new vessel systems disappear. There is a suggestion that growth hormone can worsen diabetic retinopathy. Ray et al. (1968) reported that two patients in their series promptly developed fresh retinal haemorrhages when growth hormone was given during metabolic studies after hypophysectomy.

While our results showed that the best response of diabetic retinopathy followed elimination of growth hormone reserve, it was also shown that about $60 \%$ of eyes were either improved or held unchanged in patients whose peak growth hormone level was only slightly reduced. If these results are confirmed with more cases and a longer follow-up, a reduction of growth hormone would not appear to be essential for some response to pituitary implantation.

The present study showed that there was considerable difficulty in isolating the effect of reduction of any particular pituitary hormone, because all anterior pituitary functions tended to fall in parallel after implantation. Thus adrenal function was reduced as growth hormone reserve was reduced, and so a better retinopathy response was also found as adrenal function was progressively lost. However, decreased adrenal function is unlikely to account for the improvement in retinopathy. Adrenalectomy has only occasionally improved the condition (Graef and Maier, 1962 ; Malins, 1962). Moreover, both Lourie et al. (1962) and Ray et al. (1968) have reported the case of a patient whose retinopathy was deteriorating after adrenalectomy but improved after hypophysectomy. In addition all patients in this present series undergoing complete pituitary ablation were maintained on corticosteroids.

It is possible that the mean daily growth hormone secretion was reduced in all the patients after implant, and that a reduction in the usual daily level of serum growth hormone was the dominant factor in retinopathy remission. Although growth hormone levels measured in response to insulin-induced hypoglycaemia may be the most appropriate test of the adequacy of pituitary ablation, they do not necessarily relate to the usual daily level. It may not be possible to determine the precise role of growth hormone in the improvement of retinopathy after pituitary ablation until such a daily secretion rate is measured.

One of us (E. M. K.) is in receipt of a grant from the Tobacco Research Council. The work was supported by a Medical Research Council grant for the growth hormone assay and for photographic material. We are grateful to Dr. C. T. Dollery for helpful criticism.

\section{REFERENCES}

Fankhauser, S., Teuscher, A., König, H., and Reubi, F. (1966). Helvetica Medica Acta, 33, 22.

Field, R. A. (1965). In On the Nature and Treatment of Diabetes, edited by B. S. Leibel and G. A. Wrenshall, p. 487. Amsterdam, Excerpta Medica Foundation.

Field, R. A., Schepens, C. L., Sweet, W. H., and Appels, A. (1962). Diabetes, 11, 465.

Fraser, T. R., and Wright, A. D. (1968). Postgraduate Medical fournal, 44, 53.

Graef, I., and Maier, H. C. (1962). Diabetes, 11, 485.

Hartog, M., Gaafar, M. A., Meisser, B., and Fraser, T. R. (1964). British Medical fournal, 2, 1229.

Joplin, G. F., Fraser, R., Hill, D. W., Oakley, N. W., Scott, D. J., and Doyle, F. H. (1965). Quarterly fournal of Medicine, 34, 443.

Joplin, G. F., Oakley, N. W., Hill, D. W., Kohner, E. M., and Fraser, T. R. (1967). Diabetologia, 3, 406.

Kohner, E. M., Dollery, C. T., Paterson, J. W., and Fraser, T. R. (1967). Excerpta Medica, International Congress Series, 140, 13.

Linfoot, J. A. (1967). Vascular Complications of Diabetes Mellitus, edited by S. J. Kimura and W. M. Caygill, p. 219. St. Louis, Missouri, Mosby.

Lourie, H., Moses, A., and Lloyd, C. (1962). New England fournal of Medicine, 267, 924.

Luft, R. (1962). Diabetes, 11, 461.

Malins, J. (1962). Diabetes, 11, 483.

Oakley, N., Hill, D. W., Joplin, G. F., Kohner, E. M., and Fraser, T. R.'(1967). Diabetologia, 3, 402.

Powell, E. D. U., Frantz, A. G., Rabkin, M. T., and Field, R. A. (1966). New England fournal of Medicine, 275, 922. Ray, B. S., Pazianos, A. G., Greenberg, E., Peretz, W. L., and McLean,
J. M. (1968). Fournal of the American Medical Association, 203, 79.

Teuscher, A., Fankhauser, S., Girard, J., and Wyss, F. (1966). Helvetica Medica Acta, 33, 29.

Teuscher, A., König, H., and Zahnd, G. R. (1967). Excerpta Medica. International Congress Series, 140, 22. 